\title{
Trajectories of depressive and anxiety symptoms in older adults: A 6-year prospective cohort study
}

Sophie E Holmes $\mathrm{PhD}^{1}$, Irina Esterlis $\mathrm{PhD}^{1}$, Carolyn M. Mazure, $\mathrm{PhD}^{1}$, Yen Ying Lim², David Ames, MD ${ }^{3,4}$, Stephanie Rainey-Smith, PhD ${ }^{5}$, Chris Fowler2, Kathryn Ellis ${ }^{4}$, Ralph N. Martins, $\mathrm{PhD}^{5,6}$, Olivier Salvado, $\mathrm{PhD}^{7}$, Vincent Doré,7,8, Victor L. Villemagne, $\mathrm{MD}^{2,8}$, Christopher C. Rowe, MD ${ }^{8}$, Simon M. Laws, PhD5,9,10, Colin L. Masters, MD², Robert H. Pietrzak PhD, MPH1,12 and Paul Maruff, PhD2,11 for the Australian Imaging, Biomarkers and Lifestyle Research Group

${ }_{1}^{1}$ Department of Psychiatry, Yale University School of Medicine, New Haven, CT, USA

${ }^{2}$ The Florey Institute, The University of Melbourne, Parkville, Victoria, Australia ${ }^{3}$ Academic Unit for Psychiatry of Old Age, St. Vincent's Health, Department of Psychiatry, The University of Melbourne, Kew, Victoria, Australia ${ }^{4}$ National Ageing Research Institute, Parkville, Victoria, Australia ${ }^{5}$ Centre of Excellence for Alzheimer's Disease Research and Care, School of Medical and Health Sciences, Edith Cowan University, Joondalup, Western Australia, Australia ${ }^{6}$ Sir James McCusker Alzheimer's Disease Research Unit, Hollywood Private Hospital, Perth, Western Australia, Australia

7The Commonwealth Scientific and Industrial Research Organization, Canberra, Australia 8Department of Nuclear Medicine and Centre for PET, Austin Health, Heidelberg, Victoria, Australia ${ }^{9}$ Co-operative Research Centre for Mental Health

10. School of Biomedical Sciences, Faculty of Health Sciences, Curtin Health Innovation Research Institute, Curtin University ${ }^{11}$ Cogstate Ltd., Melbourne, Victoria, Australia 12U.S. Department of Veterans Affairs National Center for Posttraumatic Stress Disorder, Clinical Neurosciences Division, VA Connecticut Healthcare System, West Haven, CT, USA

\section{Corresponding author:}

Sophie E Holmes, $\mathrm{PhD}$

Postdoctoral Associate

Yale University

Suite 511, 2 Church Street South

New Haven, CT

USA 06519

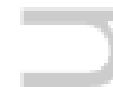

Word count: 3171
Tel: +12036854066

sophie.holmes@yale.edu

Fax: 2037646655

This is the author manuscript accepted for publication and has undergone full peer review but has not been through the copyediting, typesetting, pagination and proofreading process, which may lead to differences between this version and the Version of Record. Please cite this article as doi: $10.1002 /$ gps.4761 


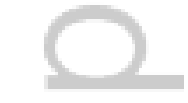

\section{Abstract}

Objective: Depressive and anxiety symptoms are common in older adults, significantly affect quality of life and are risk factors for Alzheimer's Disease. We sought to identify the determinants of predominant trajectories of depressive and anxiety symptoms in cognitively normal older adults.

Method: 423 older adults recruited from the general community underwent A $\beta$ PET imaging, $A P O E$ and $B D N F$ genotyping and cognitive testing at baseline and had follow-up assessments. All participants were cognitively normal and free of clinical depression at baseline. Latent growth mixture modeling (LGMM) was used to identify predominant trajectories of subthreshold depressive and anxiety symptoms over 6 years. Binary logistic regression analysis was used to identify baseline predictors of symptomatic depressive and anxiety trajectories.

Results: LGMM revealed two predominant trajectories of depressive and anxiety symptoms: a chronically elevated trajectory and a low, stable symptom trajectory, with almost 1 in 5 participants falling into the elevated trajectory groups. Male sex (relative risk ratio $[\mathrm{RRR}]=3.23)$, lower attentional function $(\mathrm{RRR}=1.90)$ and carriage of the $B D N F$ Val66Met allele in women (RRR=2.70) were associated with increased risk for chronically elevated depressive symptom trajectory. Carriage of the $A P O E \varepsilon 4$ allele $(\mathrm{RRR}=1.92)$ and lower executive function in women $(\mathrm{RRR}=1.74)$ were associated with chronically elevated anxiety symptom trajectory.

Conclusion: Our results indicate distinct and sex-specific risk factors linked to depressive and anxiety trajectories, which may help inform risk stratification and management of these symptoms in older adults at risk for Alzheimer's Disease. 


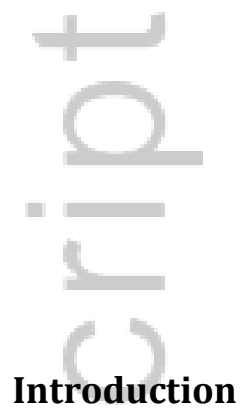

Subthreshold depressive and anxiety symptoms are defined as those that have a meaningful impact on quality of life and/or functioning but remain below the threshold necessary for formal diagnosis of a mood disorder ${ }^{1}$, 2 Subthreshold depressive and anxiety symptoms affect $15-25 \%^{3-5}$ and $24-43 \%{ }^{2,3,5}$ of older adults in the general community, respectively. These symptoms can be chronic in nature ${ }^{6,7}$, and are associated with reduced functioning and quality of life, ${ }^{3,7,8}$ as well as increased risk for Alzheimer's disease (AD) ${ }^{9}$ 10,11. Thus, such symptoms are important to identify and treat, and could be instrumental in ascertaining early manifestations of age-related neurodegenerative disease.

Support for the relationship between depressive and anxiety symptoms and AD comes from studies showing that these symptoms are associated with increased amyloid load 12,13 , 14, carriage of the apolipoprotein epsilon $4(A P O E \varepsilon 4)$ allele ${ }^{15-17}$ and the val66Met polymorphism of the brain derived neurotrophic factor $(B D N F)$ gene ${ }^{18}$, as well as with higher salivary cortisol levels 19,20 and faster cognitive decline ${ }^{21-23}$. However, to date, no study has sought to understand how markers of the AD prodrome, such as demographic 
factors (e.g., sex, education), amyloid burden, genetic risk factors (e.g., $A P O E \varepsilon 4$ ) and cognition, may relate to the longitudinal trajectory of depressive and anxiety symptoms.

\section{Aims of the study}

To address these gaps in understanding, the first aim of the current study was to identify the nature and magnitude of changes in depressive and anxiety symptoms over six years in a large cohort of cognitively normal older adults. The second aim was to evaluate AD-related biological risk factors such as amyloid level, demographic risk factors such as female sex and low education level, genetic factors such as carriage of an APOE $\varepsilon 4$ or $B D N F^{\text {val66met }}$ allele 24 , and cognitive factors such as reduced executive function and attention $^{25-29}$, as possible determinants of symptomatic trajectories of depressive and anxiety symptoms.

\section{Method}

\section{Participants}

Participants were 423 cognitively normal older adults who had undergone A $\beta$ PET imaging and genotyping as part of the Australian Imaging, Biomarkers and Lifestyle (AIBL) study of aging ${ }^{30}$ and completed clinical assessments over 6 years. Table 1 shows demographic and clinical characteristics of the sample. Exclusion criteria at entry were: a diagnosis of schizophrenia, presence of clinical depression as assessed by $\geq 6$ on the Geriatric Depression Scale [GDS-15], a diagnosis of Parkinson's disease, previous head injury with $>1$ hour of posttraumatic amnesia, cancer within the last 2 years, stroke, diabetes, obstructive sleep apnea where disclosed, and heavy regular alcohol intake. 
Medical, psychiatric and neuropsychological data were used to confirm the cognitive health and clinical classification of each participant. The institutional research and ethics committees of Austin Health, St Vincent's Health, Hollywood Private Hospital and Edith Cowan University approved the study. All participants gave written informed consent.

\section{PET imaging and genotyping}

$\mathrm{A} \beta$ imaging with PET was conducted using $\left[{ }^{11} \mathrm{C}\right] \mathrm{PiB}(\mathrm{PiB}),\left[{ }^{18} \mathrm{~F}\right]$ florbetapir $(\mathrm{FBP})$ or ${ }^{18}$ F] flutemetamol (FLUTE). Given different pharmacokinetic characteristics, a different acquisition protocol was adopted for each tracer. Thirty minute acquisitions were started 40 minutes after injection of $\mathrm{PiB}$, and 20-minute acquisitions were performed 50 minutes after injection of FBP and 90 minutes after injection of FLUTE. The outcome measure was standardized uptake value ratio (SUVR). Cerebellar cortex, whole cerebellum and pons were used as reference regions for PiB, FBP or FLUTE, respectively. The SUVR was classified dichotomously as low or high $(A \beta$ - or $A \beta+)$, with thresholds set at $1.5,1.10$ or 0.62 for PiB, FBP or FLUTE, respectively ${ }^{30}$. Blood samples were collected for APOE and BDNF genotyping, as previously described ${ }^{31}$. Morning fasted plasma cortisol levels were analyzed using a cortisol enzyme-linked immunosorbent assay (IBL International GmbH, Hamburg, Germany). PET imaging, genotyping and measurement of cortisol was performed at baseline.

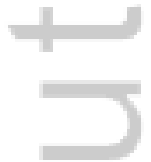

\section{Anxiety and depressive symptoms, and neuropsychological assessment}


Depressive and anxiety symptoms were assessed at baseline, and at 1.5-, 3-, 4.5-, and 6-year follow-up assessments using the Hospital Anxiety and Depression Scale (HADS) ${ }^{32}$. Cut-off scores of $\geq 8$ on the depression and anxiety subscales were used as indicative of clinically significant depression and anxiety symptoms, as recommended by the developers of the HADS $^{32}$ and consistent with a review concluding that 8 is an optimal cut-off score for the HADS subscales ${ }^{33}$. Comprehensive neuropsychological assessment was also conducted at these time points, with composite scores of cognitive functioning derived from standardized scores in relation to a large normative database ${ }^{30}$. Composite scores were computed for tests of executive function (Cogstate One-Back, Letter Fluency, Category Fluency Switching [Fruit/Furniture]); episodic memory (Logical Memory delayed recall, California Verbal Learning Test, Rey Complex Figure Test [RCFT] 3-min delayed recall, RCFT 30-min delayed recall, Cogstate One-Card Learning); language (Category Fluency [Animals/Boys' Names], Boston Naming Test); and attention (Digit Symbol, Cogstate Detection, Cogstate Identification). The calculation and validation of these composite scores have been described previously ${ }^{30}$.

\section{Data analysis}

To identify predominant trajectories of depressive and anxiety symptoms, latent growth mixture modeling (LGMM) was applied to HADS-assessed depressive and anxiety symptoms over the 6-year study period using robust full-information maximum likelihood estimation in Mplus, version 7.11. To determine the best fitting trajectories, 1- to 5-class unconditional LGMMs were compared for relative fit using conventional fit indices ${ }^{34}$. Best 
fitting models were identified based on smaller Bayesian Information Criterion and Akaike Information Criterion values, higher entropy values, and from results of the Lo-MendellRubin likelihood test and bootstrap likelihood ratio test, which quantify the likelihood that the data can be described by a model with one less trajectory. Class sizes, parsimony, and theoretical interpretability were also considered when identifying optimal solutions. To enhance generalizability, the final model selected contained a meaningful proportion of the sample $(>10 \%)$ in the smallest class. Each participant was assigned the class having the greatest posterior probability. Bivariate analyses were then used to evaluate relationship between each predictor variable and symptomatic trajectories of depressive and anxiety symptoms. Variables associated significantly $(\mathrm{p}<0.05)$ with symptomatic trajectories were then entered into binary logistic regression analyses using Forward Wald estimation to identify independent baseline predictors of symptomatic depressive and anxiety trajectories. Moderating effects of $\operatorname{sex}^{24}$ were evaluated by incorporating interaction terms (e.g. $A \beta x$ sex) into these models.

\section{Results}

As shown in Table 2, a 2-class solution was determined to be the optimal model for both depression and anxiety symptoms, fitting the data better than the 1- 3- and 4- and 5class solutions. For depressive symptoms, the 2-class model was characterized by a low/stable trajectory group, in which scores on the depressive subscale of the HADS were low at baseline and followed a stable trajectory over time $(n=346,81.8 \%$, intercept $=1.9$ (standard error $[\mathrm{SE}]=0.1$, slope $=-0.002[\mathrm{SE}=0.002]$ ) and an elevated depressive symptom 
trajectory group, characterized by persistently elevated depressive symptoms across the study period $(\mathrm{n}=77,18.2 \%$, intercept=5.3 $(\mathrm{SE}=0.5)$, slope=0.006 [SE=0.007]) (Figure 1). In this group, $16.7 \%(n=9), 9.3 \%(n=5), 22.2 \%(n=12), 20.4 \%(n=11)$, and $24.1 \%(n=13)$ screened positive for clinically significant depressive symptoms (score $\geq 8$ ) at the baseline, and 1.5-, 3-, 4.5-, and 6-year assessments, respectively.

$=$ For anxiety symptoms, the 2-class model was characterized by a stable trajectory group, characterized by lower than average anxiety HADS scores at baseline and stable trajectory of scores over time $(n=351,83.0 \%$, intercept $=3.9(\mathrm{SE}=0.2$, slope $=-0.02$ [SE=0.002]) and an elevated anxiety symptom trajectory group, characterized by higher anxiety HADS scores at baseline and a slight increase in scores over time $(n=72,17.0 \%$, intercept=5.4 (SE=0.4), slope=0.029 [SE=0.007]) (Figure 2). In this group, 33.3\% $(n=24)$, 30.6\% (n=22), 31.9\% (n=23), 41.7\% $(n=30)$, and 31.9\% $(n=23)$ screened positive for clinically significant anxiety symptoms at the baseline, and 1.5-, 3-, 4.5-, and 6-year assessments, respectively

Examination of overlap of the 2-class anxiety and depressive symptom trajectory solutions revealed that, of the elevated anxiety trajectory group, only 27 (37.5\%) were in the elevated depression trajectory group. Given this low overlap of elevated depressive and anxiety trajectories, determinants of symptomatic trajectories were examined separately. Table 3 shows results of bivariate analyses that examined how baseline demographic, biological, and cognitive variables were associated with depressive and anxiety symptom trajectories. Compared with the stable/low depressive symptom trajectory group, the elevated depressive symptom trajectory group was older, more likely to be male, and 
scored lower on baseline measures of executive function and attention; and for women, more likely to carry the $B D N F$ Met allele. Compared with the stable/low anxiety symptom trajectory, the elevated anxiety symptom trajectory group was more likely to be comprised of $A P O E \varepsilon 4$ allele carriers (a finding driven by men) and, for women, lower executive function scores were associated with an elevated anxiety symptom trajectory.

$=$ - Binary logistic regression analysis predicting an elevated depressive symptom trajectory revealed a main effect of sex, with men more likely to be in the elevated depressive symptom trajectory group than women (Wald $\mathrm{X}^{2}=7.48, p=0.005$; relative risk ratio $[R R R]=3.23,95 \%$ confidence interval $(\mathrm{CI})=1.41-7.35)$. Lower attention composite scores were also associated with greater likelihood of being in the elevated depressive symptom trajectory group (Wald $X^{2}=9.22, p=0.002 ; \mathrm{RRR}=1.90,95 \% \mathrm{CI}=1.25-2.87$ ). Further, there was a significant $B D N F \mathrm{x}$ sex interaction, with female Met allele carriers being more likely than male Met allele carriers to be in the elevated depressive symptom trajectory group (Wald $\mathrm{X}^{2}=4.41, p=0.036 ; \mathrm{RRR}=2.70,95 \% \mathrm{CI}=1.07-6.82$ ). Specifically, of female Met carriers, $63.6 \%(n=14 / 22)$ were in the elevated depressive symptom trajectory group compared to $37.1 \%(n=72 / 194)$ in the stable/low trajectory group. Main and interactive effects of $A \beta$, cortisol, $A P O E$, education level and executive function were unrelated to the elevated depressive symptom trajectory (all Wald $X^{2}<1.41$, all p's $>0.235$ )

Binary logistic regression analysis predicting an elevated anxiety symptom trajectory revealed a main effect of $A P O E \varepsilon 4$ allele carriage in predicting this trajectory (Wald $\mathrm{X}^{2}=5.41$, $p=0.020 ; \mathrm{RRR}=1.92,95 \% \mathrm{CI}=1.11-3.33)$. Of $\varepsilon 4$ carriers, $38.9 \%(\mathrm{n}=28 / 72)$ were in the elevated anxiety symptom trajectory group vs. $24.8 \%(n=87 / 351)$ in the stable/low anxiety 
trajectory group. There was also a significant interaction between executive function and sex (Wald $\mathrm{X}^{2}=5.98, p=0.014 ; \mathrm{RRR}=1.74,95 \% \mathrm{CI}=1.12-2.71$ ), with lower executive function scores in women, but not men, being linked to the elevated anxiety symptom trajectory. Main and interactive effects of $A \beta$, cortisol, $B D N F$, education level, and attention scores were unrelated to an elevated anxiety symptom trajectory (all Wald $\mathrm{X}^{2}<1.55$, all p's $>0.213$ ).

\section{Discussion}

This study is among the first to evaluate the nature and determinants of predominant longitudinal trajectories of depressive and anxiety symptoms in older adults. Results revealed that a significant proportion of older adults have a trajectory of elevated depressive (18\%) and anxiety (17\%) symptoms, which have distinct and sex-specific risk factors. Specifically, male sex, lower attentional function, and carriage of the BDNF Val66Met allele in women were linked to an elevated depressive symptom trajectory; while carriage of the $A P O E \& 4$ allele and lower executive function in women were linked to an elevated anxiety symptom trajectory. Of note, $A P O E$ status was not disclosed, so knowledge of increased AD risk was not driving symptoms.

In a previous cross-sectional study, we found that female BDNF Val66 Met carriers reported greater severity of depressive symptoms ${ }^{24}$. The current data show that this increase remains over time. $B D N F$ is important for neuronal proliferation and survival, and regulation of synaptic plasticity ${ }^{35}$. Lower CNS $B D N F$ has been proposed to be involved in the pathophysiology of depression due to a resultant reduction in neurogenic cell survival and decline in hippocampal function ${ }^{36}$. The BDNF Val66Met variant is associated with lower 
levels of $B D N F^{37}$, and there is some evidence for an association between the $B D N F$ val66Met allele and vulnerability for depression ${ }^{38}$. For example, one study found a significantly greater proportion of Met allele carriers in depressed elderly individuals compared to controls $^{39}$, supporting a role for the BDNF Met allele in depressive symptoms in older adults. Our finding that this polymorphism was linked to risk for an elevated depressive symptom trajectory in women but not men is consistent with preclinical data indicating that female but not male $B D N F$ knockout mice display a striking increase in depressive-like behavior, ${ }^{40}$ as well as human data that women with the BDNF Val66Met genotype are particularly vulnerable to social stress mediated by HPA axis activity ${ }^{41}$. This sex-specific finding also aligns with evidence that many genes act differentially in males and females ${ }^{42}$, possibly due to hormonal influences. Indeed, estrogen has a regulatory effect on $B D N F$ expression $^{43}$ and may thus underlie sex-specific associations between the BDNF Val66Met allele and an elevated depressive symptom trajectory.

Lower attentional function at baseline was also associated with a chronically elevated trajectory of depressive symptoms. This finding is consistent with research showing that lower attentional function is associated with higher levels of anxiety and depression symptoms ${ }^{44}$. For example, a large prospective study in the Netherlands found that lower attentional function in older adults at their baseline assessment was associated with an accelerated increase in depressive symptoms ${ }^{45}$. It is thought that individuals with lower attentional function may have greater difficulties with emotion regulation ${ }^{46}$. Indeed, mounting evidence from neuroimaging studies suggests that diminished top-down control from prefrontal brain regions crucial for attentional function is associated with reduced 
modulation of brain regions implicated in emotion, such as the amygdala ${ }^{47,48}$. It is also possible that older adults with depressive symptoms have limited processing efficiency due to ruminative thinking, which can preoccupy attentional resources ${ }^{49}$. Taken together, these findings suggest that interventions designed to improve attentional function, for example through the use of 'cognitive-enhancing' drugs such as modafinil50 and cognitive rehabilitation ${ }^{51}$, may help mitigate risk for chronic depressive symptoms in cognitively normal older men and women.

$A P O E \varepsilon 4$ allele carriage was associated with a chronic trajectory of anxiety symptoms, independently of $A \beta$ load. In our previous cross-sectional study, we found that $A P O E \varepsilon 4$ allele carriage was associated with greater severity of anxiety symptoms assessed at baseline, both independently and in conjunction with $A \beta$ load. Here, we did not observe an interaction between $\mathrm{A} \beta$ and $A P O E \varepsilon 4$ allele carriage in predicting a chronically elevated anxiety symptom trajectory, but did observe an independent association between APOE $\varepsilon 4$ and this outcome. A link between APOE $\varepsilon 4$ carriage and anxiety has been demonstrated previously ${ }^{53}$ and there is evidence that probable AD patients who are $A P O E \varepsilon 4$ allele carriers report greater severity of anxiety symptoms than non- $\varepsilon 4$ carriers $^{52}$. APOE $\varepsilon 4$ allele carriage is also associated with cognitive decline and increased susceptibility to $\mathrm{AD}^{53}$. Taking this together with mounting evidence indicating that anxiety can increase risk for cognitive decline $^{28,54,55}$ and dementia ${ }^{10,56}$, it is plausible that $A P O E \varepsilon 4$ allele carriage is associated with manifestation of anxiety symptoms in the first instance, thus representing an upstream risk factor for $\mathrm{AD}$. Given that $A P O E \varepsilon 4$ allele carriage is linked to an increase in the rate and extent of amyloid deposition in the brain ${ }^{57}$, increased amyloid load is likely to be involved 
in-and possibly mediates — the association between $A P O E \varepsilon 4$ allele carriage and the development and maintenance of anxiety symptoms. While our cross-sectional findings ${ }^{24}$ revealed that an interaction between $\mathrm{A} \beta$ and $A P O E \varepsilon 4$ was strongly associated with severity of anxiety symptoms in older women, this interaction was unrelated to a chronically elevated anxiety symptom trajectory. One explanation for this is that in the current study, we examined determinants of predominant trajectories of anxiety and depressive symptoms, not variance in overall symptom levels. Consequently, a reduction in statistical power (i.e., $18 \%$ of the sample showing a chronically elevated anxiety symptom trajectory) may, at least in part, account for this discrepancy between the cross-sectional and longitudinal findings.

Reduced executive function was associated with a chronically elevated anxiety symptom trajectory in women. This finding is consistent with research showing that reduced executive control over subcortical threat-related processing may be linked to anxiety $58,59,60$. For example, fMRI studies have shown that increased anxiety levels are associated with both increased amygdala response to threat distractors and with reduced activation of the PFC in response to threat-processing 58 and symptom provocation ${ }^{61}$. The finding that reduced executive function was linked to a chronically elevated anxiety symptom trajectory in women but not men may be attributable, at least in part, to ruminative thinking, which is more common in women than men ${ }^{62}$. Rumination plays a major role in anxiety-related thinking, and is thought to deplete executive resources that are necessary for cognitive regulation of emotion and behavior. Specifically, as ruminative thinking is verbal in nature, it is thought to preoccupy prefrontal circuits underlying 
executive function, and to divert attentional resources to threat-related information, which may in turn perpetuate symptoms of anxiety ${ }^{28,63}$. Women with lower executive function might therefore be at a greater risk for experiencing higher and increasing levels of anxiety over time. Interventions aimed at reducing ruminative thinking and improving executive functioning, for example through cognitive behavioral therapy ${ }^{64}$ or 'brain training'65, may minimize or prevent anxiety symptoms, which may in turn reduce the risk for cognitive decline and AD in older adults.

Methodological limitations of this study must be noted. First, the AIBL sample included a larger number of $A P O E \varepsilon 4$ carriers than is observed in the general population, as well as high levels of social class and education, and thus the results may not be generalizable to population-based samples. Second, although all of the older adults studied were cognitively normal at baseline, the sample included older adults who went on to develop MCI and AD. Additional research is needed to examine the nature and predictors of depressive and anxiety symptoms in those who went on to develop MCI or AD specifically. Third, given that the majority of older adults in our sample had subthreshold depressive and anxiety symptoms, more subtle pathological changes in these symptoms that are linked to $A \beta$ and cortisol may not have been detectable. Furthermore, the generalisability of results is limited to older adults who did not meet screening criteria for depression on the GDS at baseline, and further research is needed to examine the nature and determinants of depressive and anxiety trajectories in more psychiatrically heterogeneous samples of cognitively normal older adults. Fourth, it is possible that older adults with high levels of both depressive and anxiety symptoms are associated with distinct risk factors. A lack of 
statistical power prevented examination of this group separately, but it would be important for future research to examine the trajectories and factors associated with comorbid depressive and anxiety in older adults. Finally, other biological and psychological risk factors for depressive and anxiety symptoms, which were not assessed in the AIBL study (e.g. inflammatory markers, childhood adversity and trauma history), may also contribute to and moderate the assessed variables in predicting symptomatic trajectories of depressive and anxiety symptoms in older adults.

Notwithstanding these limitations, to our knowledge, this study is among the first to evaluate biological, demographic and cognitive factors associated with longitudinal trajectories of depressive and anxiety symptoms in older adults. Given that depressive and anxiety symptoms may be an early manifestation of neurodegenerative disease ${ }^{12,13,66 \text {, }}$ results of the current study may help to inform prevention and treatment efforts aimed at mitigating risk for cognitive decline and AD in at-risk older adults. Further research is needed to replicate these results; evaluate additional biopsychosocial factors that may additionally inform prediction of chronic depressive and anxiety symptom trajectories; and examine whether personalized therapies that target specific risk factors for chronic depressive and anxiety symptoms may help reduce these symptoms, preserve cognitive function, and mitigate risk for $\mathrm{AD}$.

\section{Acknowledgements}

Alzheimer's Australia (Victoria and Western Australia) assisted with promotion of the study and the screening of telephone calls from volunteers. We thank all the participants who underwent assessments and the staff who collected the data. Funding for the study was provided in part by the study partners (Commonwealth Scientific Industrial and Research 
Organization (CSIRO), Edith Cowan University (ECU), Mental Health Research Institute (MHRI), National Ageing Research Institute (NARI), Austin Health, CogState Ltd]. The study received support from the National Health and Medical Research Council (NHMRC) Australia via a project grant (APP1009292) awarded to SML and RNM, as well as funding from the Science and Industry Endowment Fund (SIEF) and the Cooperative Research Centre for Mental Health (CRCMH), an Australian Government Initiative. Drs. Holmes and Esterlis are supported by National Institutes of Health grants 5R01MH104459 and 1K01MH092681. Dr. Pietrzak is supported in part by the U.S. Department of Veterans Affairs National Center for Posttraumatic Stress Disorder.

\section{Declaration of Interest}

The authors report no conflicts of interest.

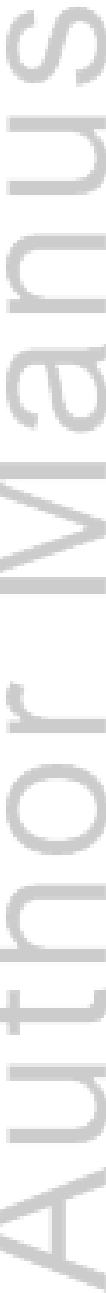

This article is protected by copyright. All rights reserved. 


\section{References}

1. Rowe SK, Rapaport MH (2006): Classification and treatment of sub-threshold depression. Current opinion in psychiatry. 19:9-13.

2. Grenier S, Préville M, Boyer R, O'Connor K, Béland S-G, Potvin O, et al. (2011): The impact of DSM-IV symptom and clinical significance criteria on the prevalence estimates of subthreshold and threshold anxiety in the older adult population. The American Journal of Geriatric Psychiatry. 19:316-326.

3. Braam AW, Copeland JR, Delespaul PA, Beekman AT, Como A, Dewey M, et al. (2014): Depression, subthreshold depression and comorbid anxiety symptoms in older Europeans: results from the EURODEP concerted action. Journal of affective disorders. 155:266-272.

4. Schoevers RA, Smit F, Deeg DJ, Cuijpers P, Dekker J, van Tilburg W, et al. (2006): Prevention of late-life depression in primary care: do we know where to begin? American Journal of Psychiatry. 163:1611-1621.

5. Kvaal K, McDougall FA, Brayne C, Matthews FE, Dewey ME (2008): Co - occurrence of anxiety and depressive disorders in a community sample of older people: results from the MRC CFAS (Medical Research Council Cognitive Function and Ageing Study). International journal of geriatric psychiatry. 23:229-237.

6. Beekman AT, Geerlings SW, Deeg DJ, Smit JH, Schoevers RS, de Beurs E, et al. (2002): The natural history of late-life depression: a 6-year prospective study in the community. Archives of general psychiatry. 59:605-611.

7. Meeks T, Vahia I, Lavretsky H, Kulkarni G, Jeste D (2011): A Tune in "A Minor" Can "B Major": A Review of Epidemiology, Illness Course, and Public Health Implications of Subthreshold Depression in Older Adults. Journal of affective disorders. 129:126-142. 8. Wilms HU, Kanowski S, Baltes MM (2000): Limitations in activities of daily living: towards a better understanding of subthreshold mental disorders in old age. Comprehensive psychiatry. 41:19-25.

9. Byers AL, Yaffe K (2011): Depression and Risk of Developing Dementia. Nature Reviews Neurology. 7:323-331.

10. Palmer K, Berger AK, Monastero R, Winblad B, Backman L, Fratiglioni L (2007): Predictors of progression from mild cognitive impairment to Alzheimer disease. Neurology. 68:1596-1602.

11. Ownby RL, Crocco E, Acevedo A, John V, Loewenstein D (2006): Depression and risk for Alzheimer disease: systematic review, meta-analysis, and metaregression analysis. Archives of general psychiatry. 63:530-538.

12. Marano C, Workman C, Lyman C, Narrow T, Zhou Y, Munro C, et al. Cortical BetaAmyloid Deposition in Late-Life Depression. The American Journal of Geriatric Psychiatry. 21:S127.

13. Lavretsky H, Siddarth P, Kepe V, Ercoli LM, Miller KJ, Burggren AC, et al. (2009): Depression and Anxiety Symptoms Are Associated with Cerebral FDDNP-PET Binding in Middle-Aged and Older Non-Demented Adults. The American journal of geriatric psychiatry: official journal of the American Association for Geriatric Psychiatry. 17:493-502. 
14. Harrington KD, Lim YY, Gould E, Maruff P (2015): Amyloid-beta and depression in healthy older adults: a systematic review. The Australian and New Zealand journal of psychiatry. 49:36-46.

15. Yen YC, Rebok GW, Gallo JJ, Yang MJ, Lung FW, Shih CH (2007): ApoE4 allele is associated with late-life depression: a population-based study. The American journal of geriatric psychiatry : official journal of the American Association for Geriatric Psychiatry. 15:858-868.

16. Caselli RJ, Reiman EM, Hentz JG, Osborne D, Alexander GE (2004): A distinctive interaction between chronic anxiety and problem solving in asymptomatic APOE e4 homozygotes. J Neuropsychiatry Clin Neurosci. 16:320-329.

17. Altmann A, Tian L, Henderson VW, Greicius MD (2014): Sex modifies the APOE related risk of developing Alzheimer disease. Annals of neurology. 75:563-573.

18. Hwang JP, Tsai SJ, Hong CJ, Yang CH, Lirng JF, Yang YM (2006): The Val66Met polymorphism of the brain-derived neurotrophic-factor gene is associated with geriatric depression. Neurobiology of aging. 27:1834-1837.

19. O'Brien JT, Lloyd A, McKeith I, Gholkar A, Ferrier N (2004): A Longitudinal Study of Hippocampal Volume, Cortisol Levels, and Cognition in Older Depressed Subjects. American Journal of Psychiatry. 161:2081-2090.

20. Mantella RC, Butters MA, Amico JA, Mazumdar S, Rollman BL, Begley AE, et al.

(2008): Salivary cortisol is associated with diagnosis and severity of late-life generalized anxiety disorder. Psychoneuroendocrinology. 33:773-781.

21. Jorm AF (2000): Is depression a risk factor for dementia or cognitive decline? Gerontology. 46:219-227.

22. Geerlings MI, BOUTER LM, SCHOEVERS R, BEEKMAN AT, JONKER C, DEEG DJ, et al. (2000): Depression and risk of cognitive decline and Alzheimer's disease. The British Journal of Psychiatry. 176:568-575.

23. Sinoff G, Werner P (2003): Anxiety disorder and accompanying subjective memory loss in the elderly as a predictor of future cognitive decline. International journal of geriatric psychiatry. 18:951-959.

24. Holmes SE, Esterlis I, Mazure CM, Lim YY, Ames D, Rainey-Smith S, et al. (2016):

Amyloid-B, APOE and BDNF Genotype, and Depressive and Anxiety Symptoms in Cognitively Normal Older Women and Men. The American Journal of Geriatric Psychiatry. 25. Lockwood KA, Alexopoulos GS, van Gorp WG (2002): Executive Dysfunction in Geriatric Depression. American Journal of Psychiatry. 159:1119-1126.

26. Sheline YI, Barch DM, Garcia K, Gersing K, Pieper C, Welsh-Bohmer K, et al. (2006):

Cognitive Function in Late Life Depression: Relationships to Depression Severity, Cerebrovascular Risk Factors and Processing Speed. Biological psychiatry. 60:58-65. 27. Beaudreau SA, O'Hara R (2009): The Association of Anxiety and Depressive Symptoms with Cognitive Performance in Community-Dwelling Older Adults. Psychology and aging. 24:507-512.

28. Beaudreau SA, O'Hara R (2008): Late-Life Anxiety and Cognitive Impairment: A Review. The American Journal of Geriatric Psychiatry. 16:790-803. 
29. Vink D, Aartsen MJ, Schoevers RA (2008): Risk factors for anxiety and depression in the elderly: A review. Journal of affective disorders. 106:29-44.

30. Lim YY, Maruff P, Pietrzak RH, Ames D, Ellis KA, Harrington K, et al. (2014): Effect of amyloid on memory and non-memory decline from preclinical to clinical Alzheimer's disease. Brain : a journal of neurology. 137:221-231.

31. Pietrzak RH, Lim YY, Ames D, Harrington K, Restrepo C, Martins RN, et al. (2015): Trajectories of memory decline in preclinical Alzheimer's disease: results from the Australian Imaging, Biomarkers and Lifestyle Flagship Study of ageing. Neurobiology of aging. 36:1231-1238.

32. Zigmond AS, Snaith RP (1983): The hospital anxiety and depression scale. Acta psychiatrica Scandinavica. 67:361-370.

33. Bjelland I, Dahl AA, Haug TT, Neckelmann D (2002): The validity of the Hospital Anxiety and Depression Scale: an updated literature review. Journal of psychosomatic research. 52:69-77.

34. Nylund KL, Asparouhov T, Muthén BO (2007): Deciding on the Number of Classes in Latent Class Analysis and Growth Mixture Modeling: A Monte Carlo Simulation Study. Structural Equation Modelling. 14:535-569.

35. McAllister AK, Katz LC, Lo DC (1999): Neurotrophins and synaptic plasticity. Annual review of neuroscience. 22:295-318.

36. Duman RS (2004): Role of neurotrophic factors in the etiology and treatment of mood disorders. Neuromolecular medicine. 5:11-25.

37. Egan MF, Kojima M, Callicott JH, Goldberg TE, Kolachana BS, Bertolino A, et al. (2003): The BDNF val66met polymorphism affects activity-dependent secretion of BDNF and human memory and hippocampal function. Cell. 112:257-269.

38. Groves J (2007): Is it time to reassess the BDNF hypothesis of depression? Molecular psychiatry. 12:1079-1088.

39. Hwang J-P, Tsai S-J, Hong C-J, Yang C-H, Lirng J-F, Yang Y-M (2006): The Val66Met polymorphism of the brain-derived neurotrophic-factor gene is associated with geriatric depression. Neurobiology of aging. 27:1834-1837.

40. Monteggia LM, Luikart B, Barrot M, Theobold D, Malkovska I, Nef S, et al. (2007): Brain-Derived Neurotrophic Factor Conditional Knockouts Show Gender Differences in Depression-Related Behaviors. Biological psychiatry. 61:187-197.

41. Shalev I, Lerer E, Israel S, Uzefovsky F, Gritsenko I, Mankuta D, et al. (2009): BDNF Val66Met polymorphism is associated with HPA axis reactivity to psychological stress characterized by genotype and gender interactions. Psychoneuroendocrinology. 34:382-388. 42. Weiss LA, Pan L, Abney M, Ober C (2006): The sex-specific genetic architecture of quantitative traits in humans. Nature genetics. 38:218-222.

43. Sohrabji F, Lewis DK (2006): Estrogen-BDNF interactions: implications for neurodegenerative diseases. Frontiers in neuroendocrinology. 27:404-414.

44. Reinholdt-Dunne ML, Mogg K, Bradley BP (2013): Attention control: Relationships between self-report and behavioural measures, and symptoms of anxiety and depression. Cognition \& emotion. 27:430-440. 
45. Vinkers DJ, Gussekloo J, Stek ML, Westendorp RG, Van der Mast RC (2004):

Temporal relation between depression and cognitive impairment in old age: prospective population based study. Bmj. 329:881.

46. Rothbart MK, Ellis LK, Posner MI (2004): Temperament and self-regulation. Handbook of self-regulation: Research, theory, and applications. 2:441-460.

47. Johnstone T, van Reekum CM, Urry HL, Kalin NH, Davidson RJ (2007): Failure to Regulate: Counterproductive Recruitment of Top-Down Prefrontal-Subcortical Circuitry in Major Depression. The Journal of Neuroscience. 27:8877-8884.

48. Disner SG, Beevers CG, Haigh EAP, Beck AT (2011): Neural mechanisms of the cognitive model of depression. Nat Rev Neurosci. 12:467-477.

49. Eysenck MW, Derakshan N, Santos R, Calvo MG (2007): Anxiety and cognitive performance: Attentional control theory. Emotion (Washington, DC). 7:336-353.

50. Husain M, Mehta MA (2011): Cognitive enhancement by drugs in health and disease. Trends in cognitive sciences. 15:28-36.

51. Priyamvada R, Ranjan R, Chaudhury S (2015): Cognitive rehabilitation of attention and memory in depression. Industrial psychiatry journal. 24:48.

52. Robertson J, Curley J, Kaye J, Quinn J, Pfankuch T, Raber J (2005): apoE isoforms and measures of anxiety in probable AD patients and Apoe-/- mice. Neurobiology of aging. 26:637-643.

53. Farrer LA, Cupples LA, Haines JL, Hyman B, Kukull WA, Mayeux R, et al. (1997): Effects of age, sex, and ethnicity on the association between apolipoprotein E genotype and Alzheimer disease: a meta-analysis. Jama. 278:1349-1356.

54. Pietrzak RH, Maruff P, Woodward M, Fredrickson J, Fredrickson A, Krystal JH, et al. (2012): Mild worry symptoms predict decline in learning and memory in healthy older adults: a 2-year prospective cohort study. The American Journal of Geriatric Psychiatry. 20:266-275.

55. Wetherell JL, Reynolds CA, Gatz M, Pedersen NL (2002): Anxiety, cognitive performance, and cognitive decline in normal aging. The Journals of Gerontology Series B: Psychological Sciences and Social Sciences. 57:P246-P255.

56. Gallacher J, Bayer A, Fish M, Pickering J, Pedro S, Dunstan F, et al. (2009): Does anxiety affect risk of dementia? Findings from the Caerphilly Prospective Study.

Psychosomatic Medicine. 71:659-666.

57. Raber J, Huang Y, Ashford JW (2004): ApoE genotype accounts for the vast majority of AD risk and AD pathology. Neurobiology of aging. 25:641-650.

58. Bishop S, Duncan J, Brett M, Lawrence AD (2004): Prefrontal cortical function and anxiety: controlling attention to threat-related stimuli. Nature neuroscience. 7:184-188. 59. Bishop SJ (2007): Neurocognitive mechanisms of anxiety: an integrative account. Trends in cognitive sciences. 11:307-316.

60. Bishop SJ (2009): Trait anxiety and impoverished prefrontal control of attention. Nature neuroscience. 12:92-98.

61. Shin LM, Rauch SL, Pitman RK (2006): Amygdala, medial prefrontal cortex, and hippocampal function in PTSD. Annals of the New York Academy of Sciences. 1071:67-79. 
62. Johnson DP, Whisman MA (2013): Gender differences in rumination: A metaanalysis. Personality and individual differences. 55:367-374.

63. Eysenck MW, Derakshan N, Santos R, Calvo MG (2007): Anxiety and cognitive performance: attentional control theory. Emotion (Washington, DC). 7:336-353.

64. Abbott MJ, Rapee RM (2004): Post-event rumination and negative self-appraisal in social phobia before and after treatment. Journal of Abnormal Psychology. 113:136.

65. Nouchi R, Taki Y, Takeuchi H, Hashizume H, Akitsuki Y, Shigemune Y, et al. (2012):

Brain training game improves executive functions and processing speed in the elderly: a randomized controlled trial. PloS one. 7:29676.

66. Korczyn AD, Halperin I (2009): Depression and dementia. Journal of the neurological sciences. 283:139-142.

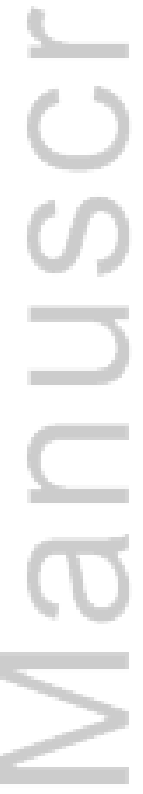

Table 1. Demographic and clinical characteristics of the sample $(n=423)$

\begin{tabular}{lcc}
\hline & $\begin{array}{c}\text { Mean (SD) or } \\
\text { n (\%) }\end{array}$ & Range \\
\hline Age & $69.4(6.6)$ & $60-89$ \\
Sex & $192(45.4 \%)$ & - \\
Male & $231(54.6 \%)$ & - \\
Female & & \\
Education & $264(62.4 \%)$ & - \\
$\quad<15$ yrs & $157(37.1 \%)$ & - \\
$>15$ yrs & $2.6(2.3)$ & $0-14$ \\
HADS depression score & $4.3(2.9)$ & $0-15$ \\
HADS anxiety score & $97(22.9 \%)$ & - \\
A $\beta+$ &
\end{tabular}

This article is protected by copyright. All rights reserved. 
$A P O E$ \&4 carrier $B D N F^{\text {Met }}$ carrier

Cortisol (ng/mL)

Executive function composite score

Attention composite score
$115(27.2 \%)$

$156(36.9 \%)$

$143.9(62.7)$

$0.01(0.8)$

$0.02(0.8)$
$19.6-522.7$

$-2.16-2.63$

$-1.67-2.41$

Note. HADS, Hospital Anxiety and Depression Scale; A $\beta+$, PET scans with above threshold levels of $\beta$-amyloid; $A P O E$ \& 4 carrier, individuals with 1 or 2 copies of the apoliprotein epsilon 4 allele; $B D N F^{\text {Met }}$ carrier, brain-derived neurotrophic factor val66Met allele carrier; SD, standard deviation

in

e.

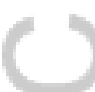

$\infty$

단.

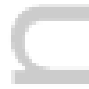

4
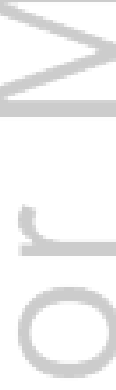

Table 2. Fit indices for 1- to 5-class unconditional latent growth mixture models of depressive and anxiety symptoms over the 6-year study period

\begin{tabular}{lccccccc}
\hline Depressive symptoms & & & & & & \\
\hline Class & $\begin{array}{c}\text { Log- } \\
\text { likelihood }\end{array}$ & AIC & BIC & SSABIC & Entropy & $\begin{array}{c}\text { LMR adjusted } \\
\text { LRT } p\end{array}$ & $\begin{array}{c}\text { \% in } \\
\text { smallest } \\
\text { class }\end{array}$ \\
\hline
\end{tabular}




\begin{tabular}{|c|c|c|c|c|c|c|c|}
\hline 1 & -3611.39 & 7242.77 & 7283.25 & 7251.51 & & & 100 \\
\hline 2 & -3567.91 & 7161.82 & 7214.44 & 7173.18 & 0.83 & 0.0042 & 18.9 \\
\hline 3 & -3554.23 & 7140.47 & 7205.23 & 7154.45 & 0.88 & 0.0656 & 0.4 \\
\hline 4 & -3531.35 & 7100.71 & 7177.61 & 7117.31 & 0.874 & 0.0863 & 0.5 \\
\hline 5 & -3523.16 & 7090.33 & 7179.37 & 7109.56 & 0.879 & 0.1974 & 0.5 \\
\hline \multicolumn{8}{|c|}{ Anxiety symptoms } \\
\hline Class & $\begin{array}{c}\text { Log- } \\
\text { likelihood }\end{array}$ & AIC & BIC & SSABIC & Entropy & $\begin{array}{l}\text { LMR adjusted } \\
\text { LRT } p\end{array}$ & $\begin{array}{c}\% \text { in } \\
\text { smallest } \\
\text { class }\end{array}$ \\
\hline 1 & -4046.79 & 8113.59 & 8154.06 & 8122.33 & & & 100 \\
\hline 2 & -4028.65 & 8083.3 & 8135.92 & 8094.67 & 0.688 & 0.0127 & 17 \\
\hline 3 & $=-4021.32$ & 8074.64 & 8139.4 & 8088.62 & 0.731 & 0.57 & 3.4 \\
\hline 4 & -4017.15 & 8072.29 & 8149.19 & 8088.9 & 0.786 & 0.19 & 0.7 \\
\hline 5 & \multicolumn{7}{|c|}{ Failure of model converg } \\
\hline
\end{tabular}

Note. AIC=Akaike Information Criterion; $\mathrm{BIC}=$ Bayesian Information Criterion; SSABIC=Sample size-adjusted Bayesian Information Criterion; LMR LRT=Lo-MendellRubin likelihood ratio test.

This article is protected by copyright. All rights reserved. 
Table 3. Results of bivariate analyses evaluating baseline correlates of predominant depression and anxiety trajectories over the 6-year study period

\begin{tabular}{|c|c|c|c|c|c|c|}
\hline & $\begin{array}{c}\text { Stable depressive } \\
\text { trajectory }\end{array}$ & $\begin{array}{c}\text { Increasing depressive } \\
\text { trajectory }\end{array}$ & $\mathrm{F}$ or $\mathrm{x}^{2}, p$ & $\begin{array}{c}\text { Stable anxiety } \\
\text { trajectory }\end{array}$ & $\begin{array}{c}\text { Increasing anxiety } \\
\text { trajectory }\end{array}$ & $\mathrm{F}$ or $\mathrm{x}^{2}, p$ \\
\hline & Mean (SE) or $n(\%)$ & & & Mean (SE) or $n(\%)$ & Mean (SE) or $n(\%)$ & \\
\hline Age & $69.0(0.34)$ & $71.8(0.95)$ & $8.53,0.004$ & $69.5(0.4)$ & $68.9(0.8)$ & $0.47,0.494$ \\
\hline Male sex & $160(43.4 \%)$ & $32(59.3 \%)$ & $4.80,0.028$ & $163(46.4 \%)$ & $29(40.3 \%)$ & $0.92,0.339$ \\
\hline Education $<15$ yrs & $116(41.6 \%)$ & $19(47.5 \%)$ & $0.50,0.478$ & $153(57.3 \%)$ & $31(59.6 \%)$ & $0.10,0.440$ \\
\hline$A P O E \& 4$ carrier (total) & $102(27.6 \%)$ & $13(24.1 \%)$ & $0.30,0.582$ & $87(24.8 \%)$ & $28(38.9 \%)$ & $6.00,0.014$ \\
\hline$A P O E \& 4$ male & $39(24.4 \%)$ & $10(31.3 \%)$ & $0.66,0.272$ & $34(20.9 \%)$ & $15(51.7 \%)$ & $12.34,0.001$ \\
\hline$A P O E \varepsilon 4$ female & $63(30.1 \%)$ & $3(13.6 \%)$ & $2.66,0.103$ & $53(28.2 \%)$ & $13(20.2 \%)$ & $0.07,0.789$ \\
\hline$B D N F^{\text {Met }}$ carrier (total) & $132(38.5 \%)$ & $30(55.6 \%)$ & $0.70,0.405$ & $125(38.5 \%)$ & $31(43.1 \%)$ & $0.52,0.470$ \\
\hline$B D N F^{\text {Met }}$ male & $60(40.3 \%)$ & $10(31.3 \%)$ & $0.90,0.342$ & $56(36.8 \%)$ & $14(48.3 \%)$ & $1.34,0.247$ \\
\hline$B D N F^{\text {Met }}$ female & $72(37.1 \%)$ & $14(63.6 \%)$ & $5.80,0.016$ & $69(39.9 \%)$ & $17(39.5 \%)$ & $0.00,0.967$ \\
\hline$A \beta+($ total $)$ & $85(23.0 \%)$ & $12(22.2 \%)$ & $0.02,0.894$ & $80(22.8 \%)$ & $17(23.6 \%)$ & $0.02,0.880$ \\
\hline $\mathrm{A} \beta+$ male & $37(23.1 \%)$ & $8(25.0 \%)$ & $0.05,0.819$ & $39(23.9 \%)$ & $6(20.7 \%)$ & $0.14,0.705$ \\
\hline$A \beta+$ female & $48(23.0 \%)$ & $4(18.2 \%)$ & $0.26,0.609$ & $41(21.8 \%)$ & $11(25.6 \%)$ & $0.29,0.593$ \\
\hline Cortisol (total) & $144.1(3.3)$ & $142.4(8.3)$ & $0.04,0.849$ & $145.4(3.4)$ & $136.2(6.7)$ & $1.28,0.258$ \\
\hline Cortisol male & $139.4(5.1)$ & $139.8(9.1)$ & $0.00,0.974$ & $141.2(5.0)$ & $130.0(9.9)$ & $0.78,0.378$ \\
\hline Cortisol female & $147.6(4.3)$ & $146.1(15.8)$ & $0.10,0.919$ & $149.1(4.7)$ & $140.3(8.9)$ & $0.68,0.411$ \\
\hline Executive function (total) & $0.05(0.04)$ & $-0.25(0.09)$ & $6.40,0.012$ & $0.04(0.04)$ & $-0.14(0.08)$ & $2.78,0.096$ \\
\hline Executive function male & $-0.07(0.06)$ & $-0.34(0.13)$ & $3.48,0.064$ & $-0.13(0.06)$ & $-0.06(0.11)$ & $0.19,0.664$ \\
\hline Executive function female & $0.14(0.06)$ & $-0.12(0.14)$ & $1.92,0.167$ & $0.18(0.06)$ & $-0.18(0.11)$ & $6.66,0.011$ \\
\hline Attention (total) & $0.06(0.04)$ & $-0.27(0.10)$ & $8.30,0.004$ & $0.05(0.04)$ & $-0.14(0.08)$ & $3.28,0.071$ \\
\hline Attention male & $0.12(0.06)$ & $-0.29(0.14)$ & $7.56,0.007$ & $0.08(0.06)$ & $-0.04(0.12)$ & $0.594,0.442$ \\
\hline Attention female & $0.007(0.5)$ & $-0.24(0.15)$ & $2.05,0.153$ & $0.02(0.06)$ & $-0.20(0.10)$ & $2.77,0.097$ \\
\hline
\end{tabular}

Note. Bolded $\mathrm{F}$ and $\mathrm{p}$ values indicate statistically significant differences between trajectory groups $(\mathrm{p}<0.05)$

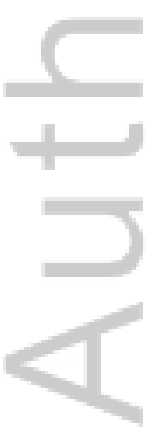

This article is protected by copyright. All rights reserved. 


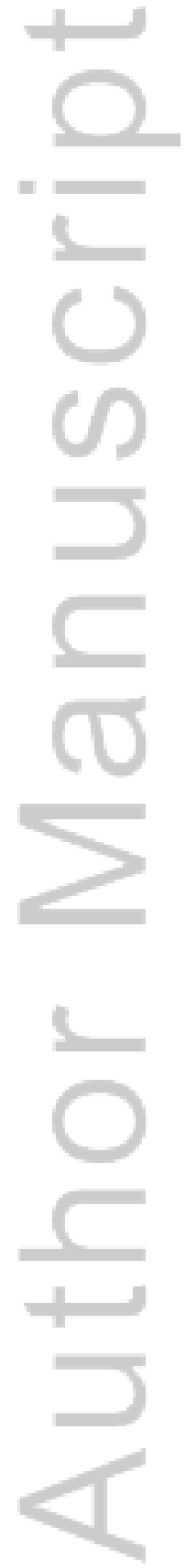

This article is protected by copyright. All rights reserved. 


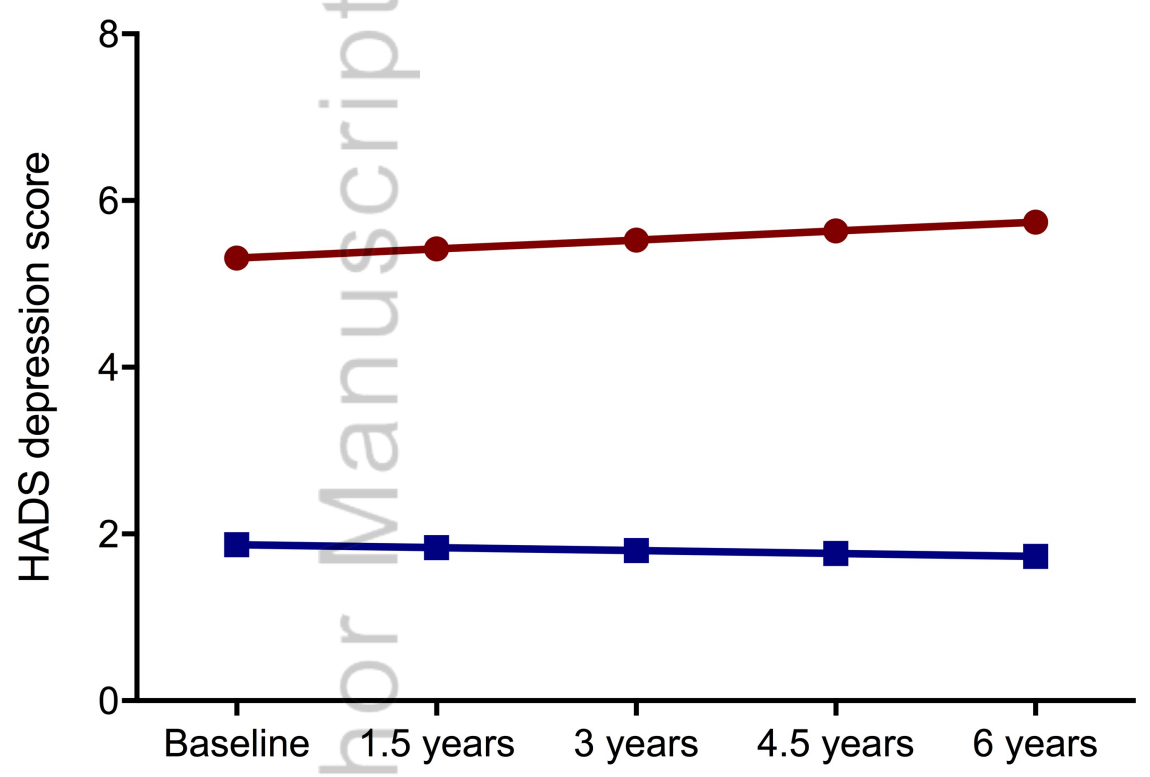

- Elevated depressive $\quad$ - Stable depressive

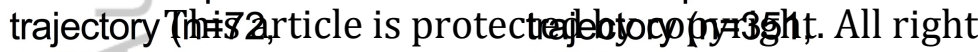
$17 \%)$ $83 \%)$ 


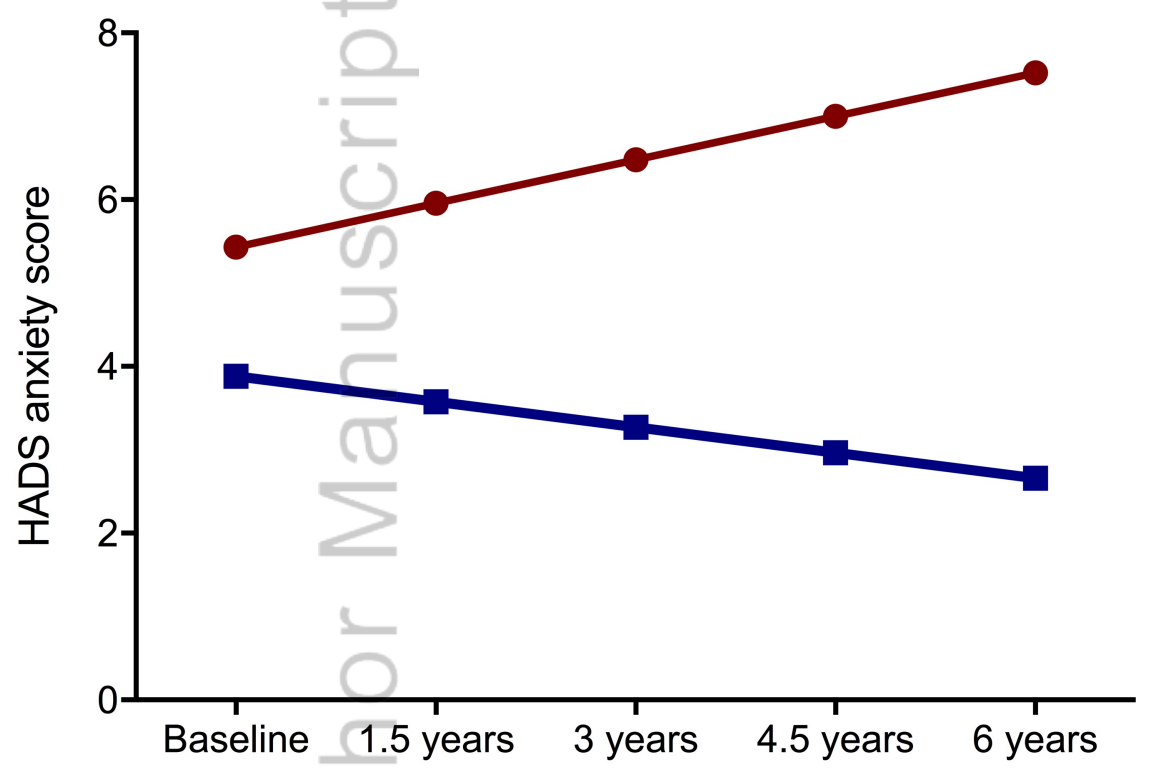

- Elevated anxiety Stable anxiety

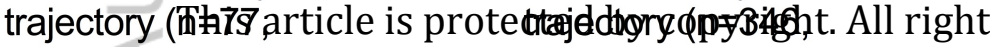
$18 \%)$

$72 \%)$ 


\section{University Library}

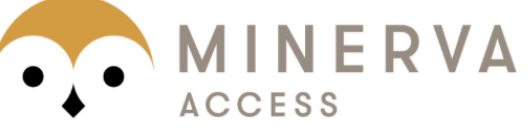

A gateway to Melbourne's research publications

Minerva Access is the Institutional Repository of The University of Melbourne

\section{Author/s:}

Holmes, SE;Esterlis, I;Mazure, CM;Lim, YY;Ames, D;Rainey-Smith, S;Fowler, C;Ellis,

K;Martins, RN;Salvado, O;Dore, V;Villemagne, VL;Rowe, CC;Laws, SM;Masters, CL;Pietrzak, $\mathrm{RH}$;Maruff, $\mathrm{P}$

Title:

Trajectories of depressive and anxiety symptoms in older adults: a 6-year prospective cohort study

\section{Date:}

2018-02-01

\section{Citation:}

Holmes, S. E., Esterlis, I., Mazure, C. M., Lim, Y. Y., Ames, D., Rainey-Smith, S., Fowler, C., Ellis, K., Martins, R. N., Salvado, O., Dore, V., Villemagne, V. L., Rowe, C. C., Laws, S. M., Masters, C. L., Pietrzak, R. H. \& Maruff, P. (2018). Trajectories of depressive and anxiety symptoms in older adults: a 6-year prospective cohort study. INTERNATIONAL JOURNAL OF GERIATRIC PSYCHIATRY, 33 (2), pp.405-413. https://doi.org/10.1002/gps.4761.

Persistent Link:

http://hdl.handle.net/11343/293215 